Nat. Hazards Earth Syst. Sci., 18, 2261-2271, 2018

https://doi.org/10.5194/nhess-18-2261-2018

(C) Author(s) 2018. This work is distributed under

the Creative Commons Attribution 4.0 License.

\title{
Stability assessment of roadbed affected by ground subsidence adjacent to urban railways
}

\author{
Sang-Soo Jeon ${ }^{1}$, Young-Kon Park ${ }^{2}$, and Ki-Young Eum ${ }^{3}$ \\ ${ }^{1}$ Department of Civil and Urban Engineering, Inje University, Inje-Ro 197, Gimhae City, \\ Kyungsangnam-Do 50834, South Korea \\ ${ }^{2}$ Smart station research team, Korea Railroad Research Institute, Chuldobakmulgwan-Ro 176, \\ Uiwang City, Gyeonggi-Do 16105, South Korea \\ ${ }^{3}$ Advanced infrastructure research team, Korea Railroad Research Institute, Chuldobakmulgwan-Ro 176, \\ Uiwang City, Gyeonggi-Do 16105, South Korea
}

Correspondence: Sang-Soo Jeon (ssj@inje.ac.kr)

Received: 17 November 2017 - Discussion started: 14 December 2017

Revised: 10 June 2018 - Accepted: 19 July 2018 - Published: 24 August 2018

\begin{abstract}
In recent years, leakages in aged pipelines for water and sewage in urban areas have frequently induced ground loss, resulting in cavities and ground subsidence, causing roadbed settlement greater than the allowable value. In this study, FLAC $^{3 \mathrm{D}}$, which is a three-dimensional finitedifference numerical modeling software, is used to perform stability and risk level assessment for the roadbed adjacent to urban railways with respect to various groundwater levels and the geometric characteristics of cavities. Numerical results show that roadbed settlement increases as the diameter $(D)$ of the cavity increases and the distance $(d)$ between the roadbed and the cavity decreases. The regression analyses results show that, as $D / d$ is greater than 0.2 and less than 0.3 , the roadbed is in the status of caution or warning. It requires a database of measurement sensors for realtime monitoring of the roadbed, structures and groundwater to prevent disasters in advance. As $D / d$ exceeds 0.35 , the roadbed settlement substantially increases and the roadbed is in danger. Since this may result in highly probable traffic accidents, train operation should be stopped and the roadbed should be reinforced or repaired. The effects of groundwater level on roadbed settlement are examined and the analysis results indicate that roadbed settlement is highly influenced by groundwater levels to an extent greater than even the influence of the size of the cavity.
\end{abstract}

\section{Introduction}

Urban railways in South Korea have been initiated from the first Seoul subway line in 1974 and have been operating in Seoul and several metropolitan cities. The number of passengers using urban railways is increasing and the railway has played a significant role in public transportation for urban development. Urban railway is defined as a transportation facility and method for smooth transportation in the city and includes light rail transit and the subway as indicated in the law of urban railway (Ministry of Land, 2015).

Risk management associated with safety is a fundamental focus in railway operations. It has been integrated into global safety management systems of railways (Berrado et al., 2010) and developed to allow a rapid risk assessment using a common risk score matrix (Braband, 2012). As roadbed settlements exceed the allowable limits, it may result in track irregularity and derailments of trains, causing heavy loss of life. Therefore, risk management tools are developed to deal with track safety by controlling and reducing the risk of derailments (Zarembski and Palese, 2006). In this study, methods to secure the stability of roadbeds have been examined using numerical analysis.

Numerical analyses have been widely used for risk assessment. Numerical analyses using three-dimensional geotechnical codes were carried out to predict the subsidence area and its interaction with buildings (Castellanza et al., 2015), and a three-dimensional groundwater flow model for risk evaluation was developed to be an effective management 
strategy (Ashfaque et al., 2017). The coupling of numerical models and monitoring data contributes to undertaking efficient risk reduction policies (Bozzano et al., 2013). Especially using FLAC, which is a finite-difference numerical code specialized in the area of geotechnical engineering, numerical computations to simulate the influence of rainfall (Pisani et al., 2010), both acoustic emission (AE) activities at $\mathrm{AE}$ sensor locations of the Kannagawa cavern (Cai et al., 2007) and a comprehensive pump test at Sellafield (Hakami, 2001), showed good agreement with field monitoring results. In this study, FLAC ${ }^{3 D}$, which is a three-dimensional finitedifference numerical code especially specialized in the area of geotechnical engineering, is adopted for numerical analysis.

Research on stability assessment and reinforcement of railway roadbeds has been actively carried out, but the effect of the cavity adjacent to urban railways on roadbed behavior has rarely been studied. In recent years, the number of accidents induced by cavities larger than $2 \mathrm{~m}$ in diameter has increased, especially in highly populated cities in South Korea. Ground subsidence near subways due to self-weight and/or surcharge loading was around $60 \%$ (Lee and Kang, 2014). Changes in groundwater levels (GWLs) may cause increased occurrences of ground subsidence because the lowering of GWLs leads to ground settlement (J. H. Lee et al., 2015). GWL influences both ground settlement and stability of underground structures. Deep excavation of the ground adjacent to urban railways has a significant influence on the allowable tensile strength of underground structures (Lee at al., 2017). If large underground cavities are located at nearby roadbeds, there is a high potential of ground subsidence.

Ground subsidence (Fig. 1) in South Korea occurred at nearby urban railways most recently (Kyunghang Times, 2016a). The ground subsidence (Fig. 1a) occurred with a cavity with a depth of $5 \mathrm{~m}$, width of $8 \mathrm{~m}$, and length of $80 \mathrm{~m}$ near the Seokchon subway station in Seoul. The accident was induced by inappropriate deep excavation near the subway. The ground subsidence (Fig. 1b) was caused by the leakage of a water pipeline with a large-scale cavity with a depth of $21 \mathrm{~m}$, width of $11 \mathrm{~m}$, and length of $12 \mathrm{~m}$ near Bakchon subway station in Incheon (Newshankuk, 2016). The ground subsidence (Fig. 1c) occurred near Samseongjungang subway station. Six cavities were found almost simultaneously in Seoul (Kyunghang Times, 2016b). A small-scale cavity with a depth of $2.2 \mathrm{~m}$ (Fig. 1d) occurred near Janghanpyeong subway station in Seoul, but the cause of this accident has not been clarified. The accident was assumed to be caused by inappropriate construction near the subway extension.

Ground subsidence with a cavity with a depth of $3.6 \mathrm{~m}$ (Fig. 1e) occurred as the replacement work of a sewage pipeline was carried out at Texas in the US (Wikitree, 2016). Ground subsidence with a cavity with a width of $15 \mathrm{~m}$ (Fig. 1f) occurred as tunnel excavation work for a subway extension was carried out at Fukuoka in Japan (Chosun Ilbo, 2016). Ground subsidence with a cavity with a width of $25 \mathrm{~m}$
(Fig. 1g) occurred as a $50 \mathrm{~m}$ tunnel excavation near the light rail transit was carried out at Ottawa in Canada (Yonhap news, 2016). Ground subsidence with a cavity with a depth of $10 \mathrm{~m}$ (Fig. 1h) occurred as subway construction was carried out near Guangzhou in China (Sisa China, 2016). Ground subsidence with large-scale cavities in urban areas is highly correlated with the undiscerned development of urban areas, abuse of groundwater and inappropriate underground construction.

A total of $80 \%$ of the ground subsidence occurring from 2010 until the beginning of 2014 in Seoul was induced by aged pipelines for water and sewage (Oh et al., 2015) since $48 \%$ and $30 \%$ of sewage pipelines in Seoul were constructed more than 30 and 50 years ago, respectively. Aged pipelines for water and sewage could cause numerous cavities in the near future (Segye Ilbo, 2016).

As a cavity exists at the center of the railway track in the box structures of urban railways, its influence on box structures and roadbed settlements has been examined to observe the effects of cavities adjacent to the roadbeds of urban railways (S. J. Lee et al., 2015). A method to establish a database was proposed to prevent and manage the disasters (Choi et al., 2007).

As a cavity exists adjacent to the roadbed, in this study, a three-dimensional numerical analysis using FLAC $^{3 \mathrm{D}}$ is carried out to assess both roadbed stability and risk level with respect to the distance between the center of the roadbed and the center of the cavity, diameter of the cavity, and GWLs.

\section{Numerical analysis}

The FLAC ${ }^{3 \mathrm{D}}$ details given in this work are briefly described in the following sections by paraphrasing from those of Itasca Consulting Group (2002).

\subsection{Theoretical background of FLAC ${ }^{3 D}$}

FLAC $^{3 \mathrm{D}}$ (Fast Lagrangian Analysis of Continua in 3 Dimensions) is a numerical modeling software for advanced geotechnical analysis of soil, rock, groundwater, and ground support in three dimensions. FLAC is used for analysis, testing, and design by geotechnical, civil, and mining engineers (Itasca Consulting Group Inc., 2002). It is designed to accommodate any kind of geotechnical engineering project that requires continuum analysis. The mechanics of the medium are derived from general principles (definition of strain, laws of motion), and the use of constitutive equations defining the idealized material. The resulting mathematical expression is a set of partial differential equations, relating mechanical (stress) and kinematic (strain rate, velocity) variables, which are to be solved for particular geometries and properties, given specific boundary and initial conditions. An important aspect of the model is the inclusion of the equations of motion, although $\mathrm{FLAC}^{\mathrm{BD}}$ is primarily concerned with the 
(a)

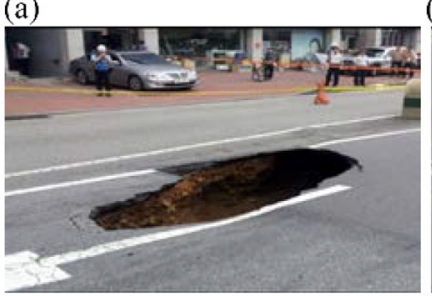

(e)

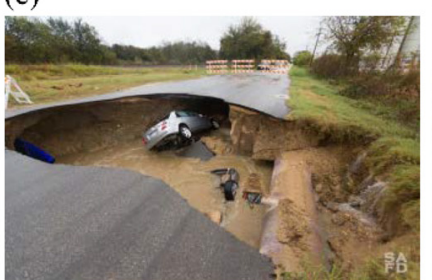

(b)

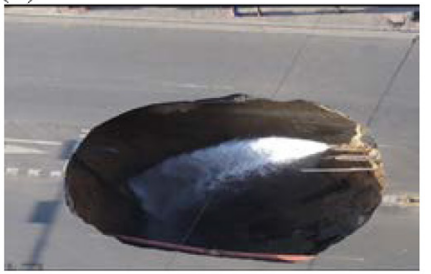

(f)

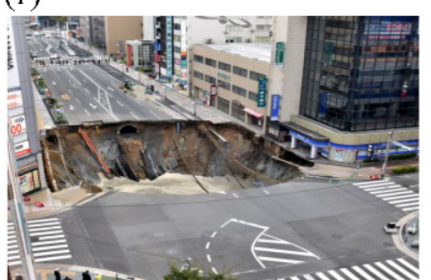

(c)

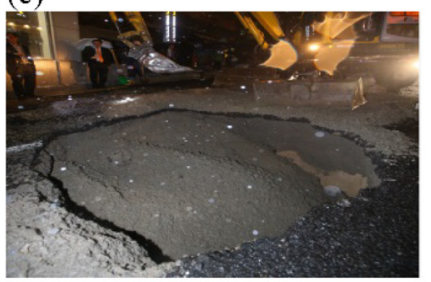

(g)

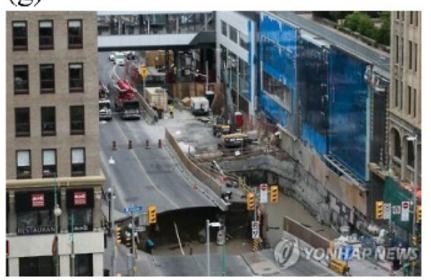

(d)

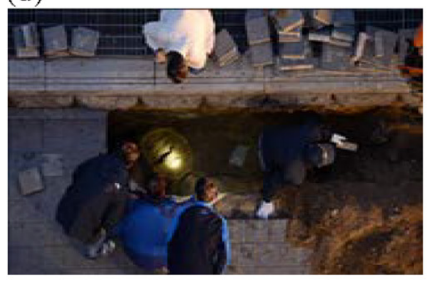

(h)

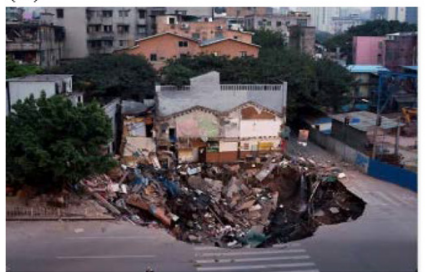

Figure 1. Ground subsidence near subways: (a) Seokchon subway station, (b) Bakchon subway station, (c) Samseongjungang subway station, (d) Janghanpyeong subway station in South Korea, (e) Texas in the US, (f) Fukuoka in Japan, (g) Ottawa in Canada and (h) Guangzhou in China.

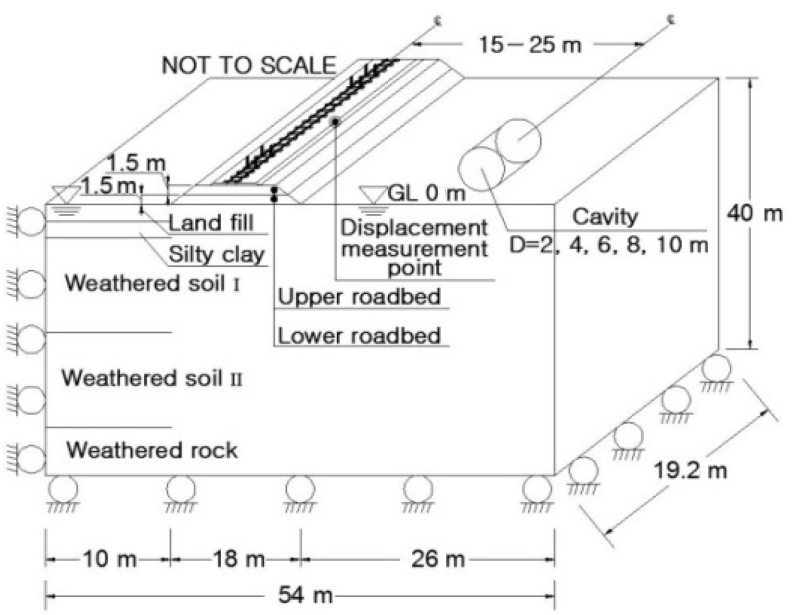

Figure 2. Configuration of the railway roadbed and cavity.

state of stress and deformation of the medium near the state of equilibrium. Application of the continuum form of the momentum principle yields Cauchy's equation of motion:

$\sigma_{i j, j}+\rho b_{i}=\rho(\mathrm{d} v i / \mathrm{d} t)$,

where $\sigma$ is the symmetric stress tensor, $\rho$ is the mass per unit volume of the medium, $[b]$ is the body force per unit mass, and $\mathrm{d}[v] / \mathrm{d} t$ is the material derivative of the velocity. These laws govern, in the mathematical model, the motion of an elementary volume of the medium from the forces applied to it. Note that in the case of static equilibrium of the medium, the acceleration $\mathrm{d}[v] / \mathrm{d} t$ is zero, and Eq. (1) reduces to the partial differential equation of equilibrium:

$\sigma_{i j, j}+\rho b_{i}=0$.

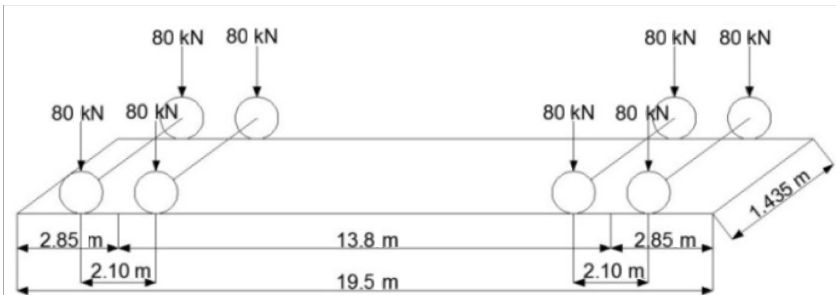

Figure 3. Configuration of the train load.

\subsection{Conditions for numerical analysis}

The Mohr-Coulomb failure model has been used for the analysis (Itasca Consulting Group Inc., 2002, 2016). Since there are various causes and sizes of the cavities of ground subsidence occurring near urban railways, it is very difficult to simulate the process of cavity generation. A circular cavity below the ground surface has been modeled with respect to diameters $(D)$ of $4-10 \mathrm{~m}$, which is selected by historical events as described in the previous section. Distances of 15$25 \mathrm{~m}$ from the cavity to the center of the roadbed and various GWLs are arbitrarily selected for roadbed settlement influenced by the given size of the cavity. The analysis is performed based on the configuration of the analysis (Fig. 2). As shown in the figure, roller supports prevent normal translations but are capable of tangential translations and/or rotations. There is a single linear reaction force either vertically or horizontally.

An embankment consists of the lower roadbed, upper roadbed and gravel ballast. The roadbed width at the bottom of the ballast is $8 \mathrm{~m}$. The widths of its bottom and top are 5.1 and $3.3 \mathrm{~m}$, respectively, and its slope is $1: 1.8$. In situ soil consists of reclaimed soil, silty clay, weathered soil and 
Table 1. Physical properties of soil, rail, PC sleeper and the rail pad.

\begin{tabular}{|c|c|c|c|c|c|c|c|c|c|}
\hline & Soil type & $\begin{array}{r}\text { Height } \\
(\mathrm{m})\end{array}$ & $\begin{array}{l}\text { Unit weight } \\
\left(\mathrm{kN} \mathrm{m}^{-3}\right)\end{array}$ & $\begin{array}{r}\text { Elastic } \\
\text { modulus }(\mathrm{kPa})\end{array}$ & $\begin{array}{r}\text { Poisson's } \\
\text { ratio }(v)\end{array}$ & $\begin{array}{r}\text { Cohesion } \\
(\mathrm{kPa})\end{array}$ & $\begin{array}{r}\text { Friction } \\
\text { angle }\left(^{\circ}\right)\end{array}$ & $\begin{array}{r}\text { Coefficient of } \\
\text { permeability }\left(\mathrm{cm} \mathrm{s}^{-1}\right)\end{array}$ & $K_{o}$ \\
\hline \multirow[t]{8}{*}{ Soil } & Ballast stone & 0.3 & 19.0 & 133900 & 0.30 & - & 35 & - & 0.43 \\
\hline & Upper roadbed & 1.5 & 18.0 & 81600 & 0.20 & 3.0 & 32 & - & 0.47 \\
\hline & Lower roadbed & 1.5 & 18.0 & 51000 & 0.30 & 10.0 & 30 & - & 0.50 \\
\hline & Land fill & 1.5 & 17.0 & 30000 & 0.35 & 5.0 & 24 & $1.0 \times 10^{-3}$ & 0.59 \\
\hline & Silty clay & 1.5 & 17.0 & 20000 & 0.35 & 5.0 & 25 & $5.0 \times 10^{-4}$ & 0.58 \\
\hline & Weathered soil I & 15.0 & 19.0 & 75000 & 0.33 & 10.0 & 30 & $1.0 \times 10^{-4}$ & 0.50 \\
\hline & Weathered soil II & 15.0 & 19.0 & 70000 & 0.33 & 10.0 & 33 & $1.0 \times 10^{-4}$ & 0.46 \\
\hline & Weathered rock & 7.0 & 20.0 & 110000 & 0.31 & 60.0 & 42 & $1.0 \times 10^{-5}$ & 0.33 \\
\hline
\end{tabular}

\begin{tabular}{|c|c|c|c|c|c|}
\hline & \multirow[t]{2}{*}{$\begin{array}{r}\text { Area } \\
\left(\mathrm{mm}^{2}\right)\end{array}$} & \multirow[t]{2}{*}{$\begin{array}{l}\text { Unit weight } \\
\qquad\left(\mathrm{kN} \mathrm{m}^{-3}\right)\end{array}$} & \multirow[t]{2}{*}{$\begin{array}{r}\text { Elastic } \\
\text { modulus }(\mathrm{kPa})\end{array}$} & \multicolumn{2}{|c|}{$\begin{array}{l}\text { Moment of inertia } \\
\qquad\left(\mathrm{m}^{4}\right)\end{array}$} \\
\hline & & & & $I_{X X}$ & $I_{Y Y}$ \\
\hline \multirow[t]{2}{*}{ KS60 rail } & 7,741 & 77.5 & $21000 \times 10^{4}$ & $30820 \times 10^{-9}$ & $5120 \times 10^{-9}$ \\
\hline & $\begin{array}{r}\text { Length } \\
(\mathrm{m})\end{array}$ & $\begin{array}{r}\text { Width } \\
(\mathrm{m})\end{array}$ & $\begin{array}{r}\text { Height } \\
(\mathrm{m})\end{array}$ & \multicolumn{2}{|c|}{$\begin{array}{r}\text { Interval between } \\
\text { sleepers }(\mathrm{m})\end{array}$} \\
\hline \multirow[t]{2}{*}{ PC sleeper } & 2.45 & 0.28 & 0.20 & & 0.58 \\
\hline & $\begin{array}{r}\text { Thickness } \\
(\mathrm{mm})\end{array}$ & & $\begin{array}{r}\text { Unit weight } \\
\left(\mathrm{kN} \mathrm{m}^{-3}\right)\end{array}$ & \multicolumn{2}{|c|}{$\begin{array}{r}\text { Vertical spring coefficient } \\
\text { of rail pad }(\mathrm{kPa})\end{array}$} \\
\hline Rail pad & 5 & & 11.5 & & $15.3 \times 10^{7}$ \\
\hline
\end{tabular}

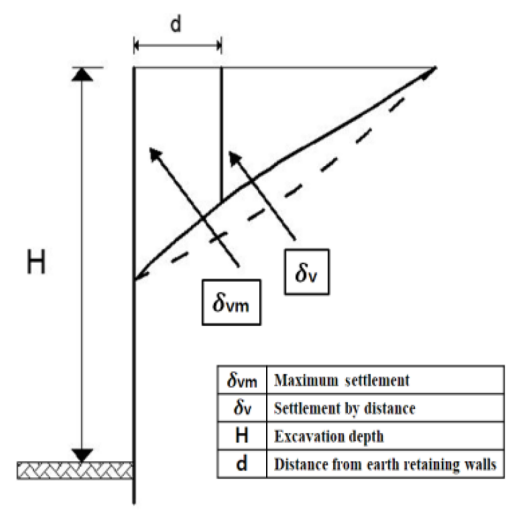

(a)

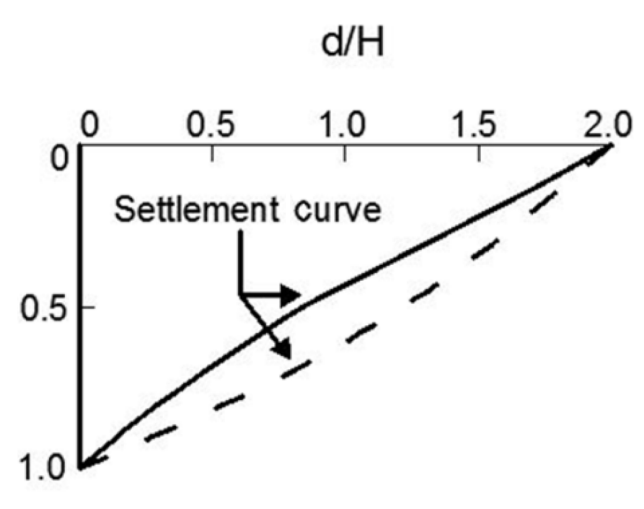

(b)

Figure 4. Settlement of clay and sand backfill with respect to the distance from earth retaining walls: (a) settlement of backfill and (b) prediction of settlement.

weathered rock. Its physical properties listed in Table 1 are obtained from lab experiments of soil sampled at a construction site.

KS60 rail and prestressed concrete (PC) sleeper commonly used in gravel ballast have been used for the numerical analysis. A rail pad, which is widely used to minimize vibration and impact loading during train operation, is made of ethylene vinyl acetate (EVA). However, in this study, a thermoplastic polyurethane (TPU) rail pad, which is more economical and has higher tensile strength has been used for the numerical analysis. Its properties are listed in Table 1. The beam element is used for the rail and rail pad.

An axial load of the urban railway train (16t) is applied for the numerical analysis. The effective loading is estimated by multiplying 1.2 with half of the axial load considering a wheel loading increment of $20 \%$ and a marginal safety of deficiency of the cant. Dynamic loading to reflect the dynamic impact ratio (Fig. 3) was estimated by multiplying 1.2 with the effective loading (Ministry of Land, 2015). 
(a)
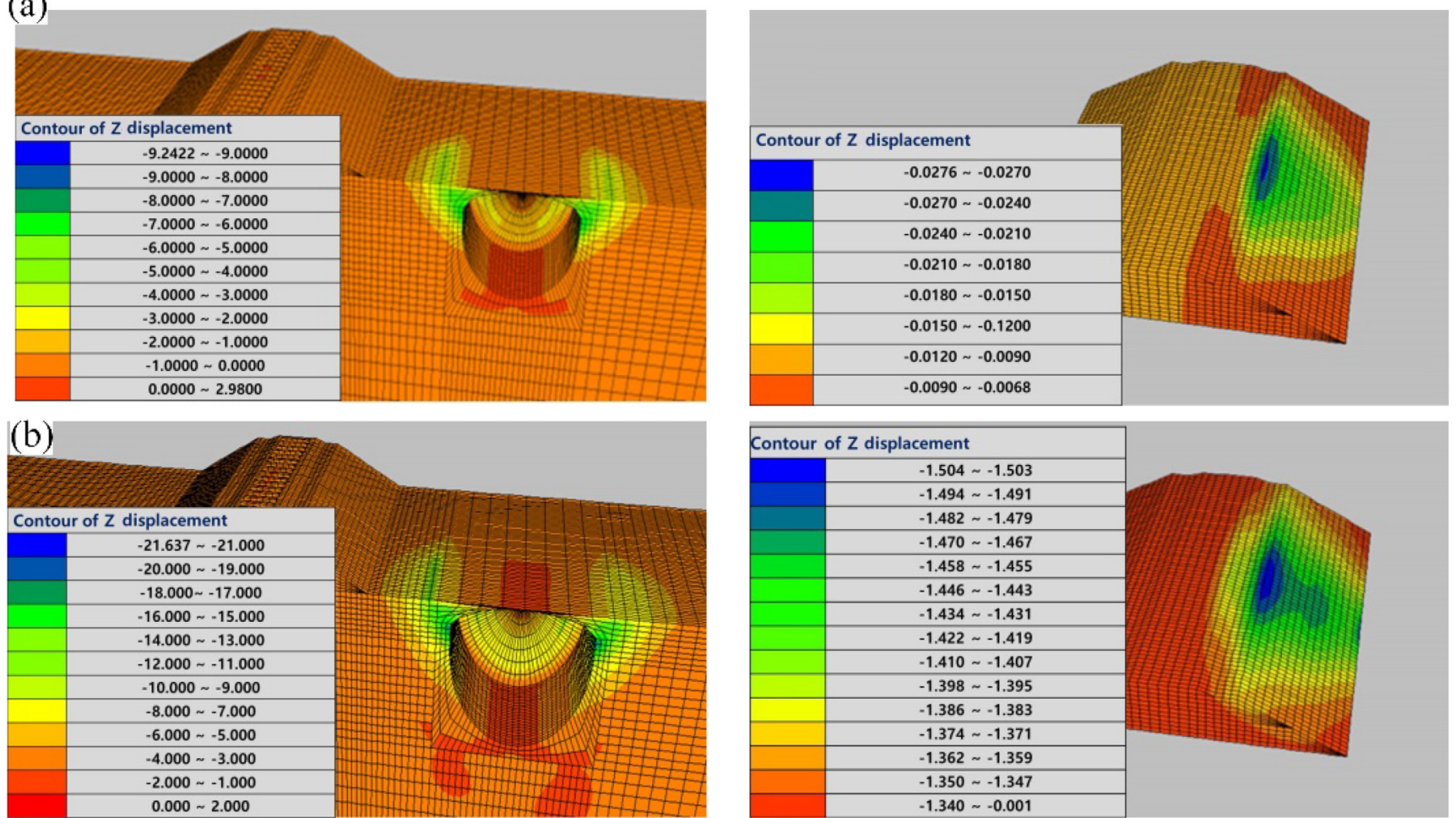

Figure 5. Vertical displacement contour of the roadbed at a distance of $20 \mathrm{~m}$ between the center of the roadbed and the center of the cavity $=20 \mathrm{~m}$ with respect to diameter of the cavity: (a) diameter $=8 \mathrm{~m}$ and (b) diameter $=10 \mathrm{~m}$.

In general, an allowable settlement of $10 \mathrm{~mm}$ has been recommended in South Korea. The vibratory loading induces a loose state in the gravel, and frequent repairs of ballasts are required. Therefore, an allowable settlement of $2.5 \mathrm{~mm}$ is used to attain additional marginal safety considering the compressive displacement of both the rail pad and ballasts, settlement of rail, ride quality, and both water inflow and cracks in the pavement surface of roadbeds (Jeon, 2014).

\section{Results and discussion}

\subsection{Roadbed settlement}

The ground settlement in the backfill area due to the excavation work has been estimated (Kojima et al., 2005; Kung et al., 2009; Ou et al., 2013) and its effect on responses of adjacent buildings has been investigated (Lin et al., 2017; Sabzi and Fakher, 2015; Schuster et al., 2009). Clough and O'Rourke (1990) have proposed the method to estimate settlement in clay and sandy soils for in situ wall systems using field measurement data and finite element analysis (Fig. 4). $H, d, \delta_{\mathrm{vm}}$ and $\delta$ represent an excavation depth, a distance from the wall, the maximum settlement and a settlement with respect to the distance, respectively. The settlements tend to average about $0.15 \% H . \delta_{\mathrm{vm}}$ occurs in the middle of excava- tion depth near the wall and a settlement linearly decreases as $d$ increases. Little settlement occurs as $d=2 H$. Empirical correlations of settlement with $d$ proposed by Bowels (1998) and Peck (1969) were similar to the one proposed by Clough and O'Rourke (1990). Bowels (1998) suggested that the settlements tend to average about $0.13 \%-0.18 \% \mathrm{H}$. The magnitude of settlements is influenced by the ground stiffness, the wall stiffness and support spacing. In this study, although ground is not fully excavated and also there are no wall systems, the settlement resulting from stress release in ground similarly occurs.

The contours of ground settlement are presented for how the roadbed (Fig. 5) is influenced by a cavity adjacent to the urban railways. The contours of ground settlement are presented for cavities with diameters of 8 and $10 \mathrm{~m}$ at a distance of $20 \mathrm{~m}$ between the center of the roadbed and the center of the cavity. As shown in the figures, ground settlement increases as the diameter of the cavity increases. As a cavity is generated on the right side of the roadbed, the right end of the roadbed is significantly settled down.

The analysis results (Fig. 6) are presented for cavities with diameters of $4-10 \mathrm{~m}$. As the variation from 15 to $20 \mathrm{~m}$ in the distances between the center of the roadbed and the center of the cavity is applied to the $10 \mathrm{~m}$ cavity, roadbed settlements are calculated with respect to various diameters of the cavity. The cavity with a diameter of $10 \mathrm{~m}$ at a distance of 

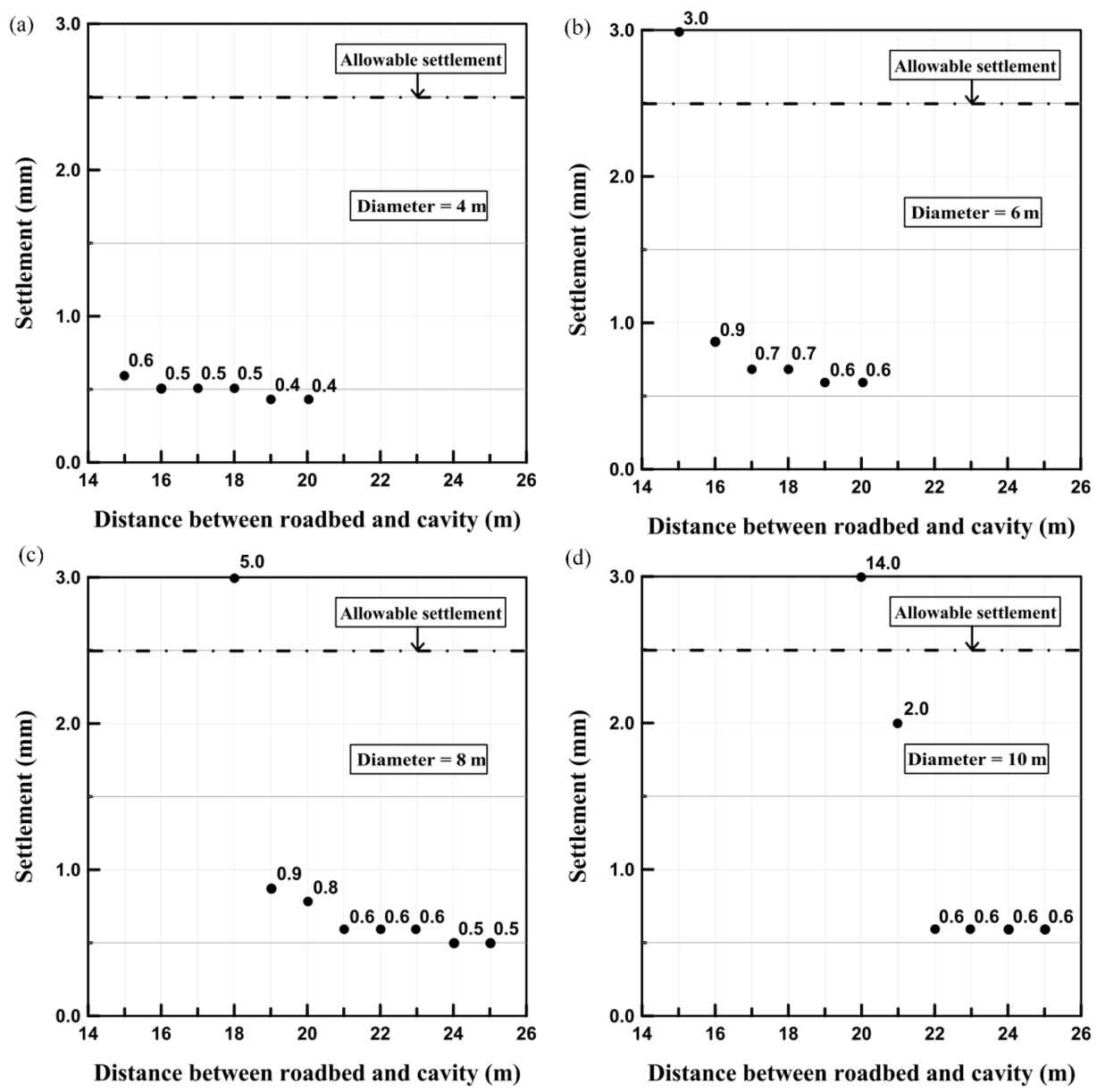

Figure 6. Roadbed settlement with respect to the distance between roadbed and cavity: (a) diameter $=4 \mathrm{~m}$, (b) diameter $=6 \mathrm{~m}$, (c) diameter $=8 \mathrm{~m}$ and $(\mathbf{d})$ diameter $=10 \mathrm{~m}$.

$20 \mathrm{~m}$ has little influence on the roadbed. However, as the diameter of the cavity at the same distance exceeds $10 \mathrm{~m}$, the roadbed settlement exceeds the allowable value. As cavities with diameters of 8 and $6 \mathrm{~m}$ are generated, at distances less than 18 and $15 \mathrm{~m}$, where $d$ is close to or less than $2 H(2 D)$, the roadbed settlement may exceed the allowable settlement, resulting in an accident.

Roadbed settlement increases as the diameter $(D)$ of the cavity increases and the distance $(d)$ between the roadbed and the cavity decreases. Therefore, in this study, the roadbed settlement is examined with respect to $D$ normalized by $d$ (Fig. 7). The regression analyses results show medium to high correlations of $r^{2}=0.72$. As $D / d$ is greater than 0.2 and less than 0.3 , the roadbed settlement is approximately $5 \mathrm{~mm}$. A database of measurement sensors should be established for real-time monitoring of the roadbed, structures and groundwater to prevent disasters in advance. As $D / d$ exceeds 0.35 , the roadbed settlement substantially increases and is greater than $10 \mathrm{~mm}$. Since it may result in highly probable traffic accident, train operation should be stopped and the roadbed should be reinforced or repaired.

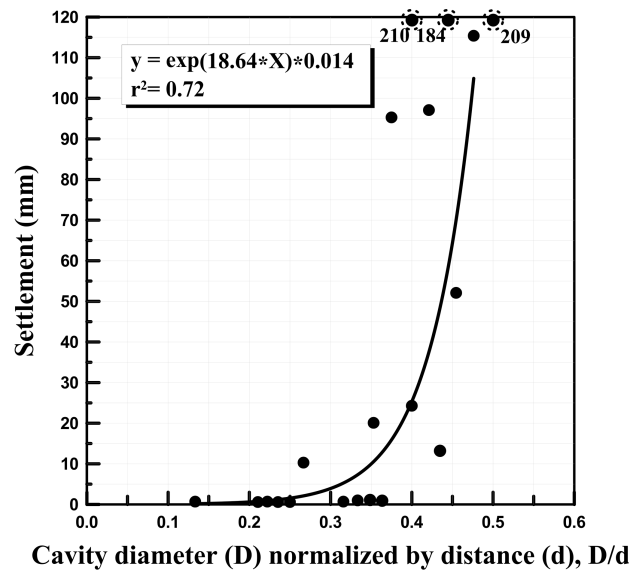

Figure 7. Regression analysis of roadbed settlements with respect to the diameter of the cavity and distance between the roadbed and the cavity. 


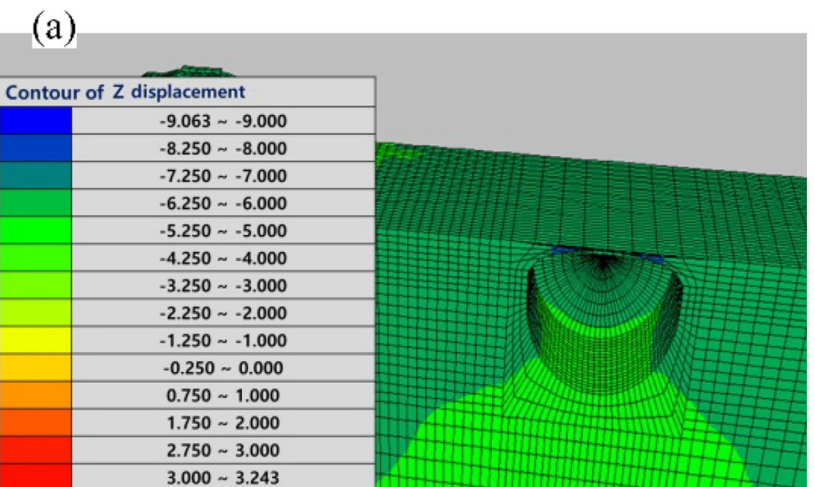

(b)

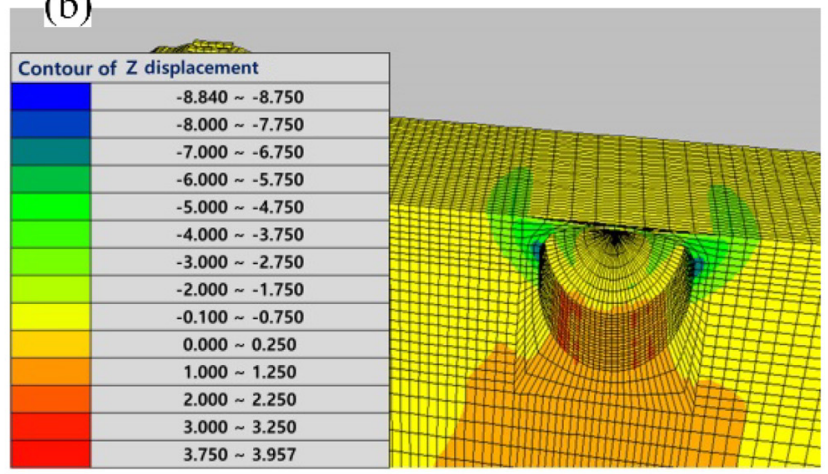

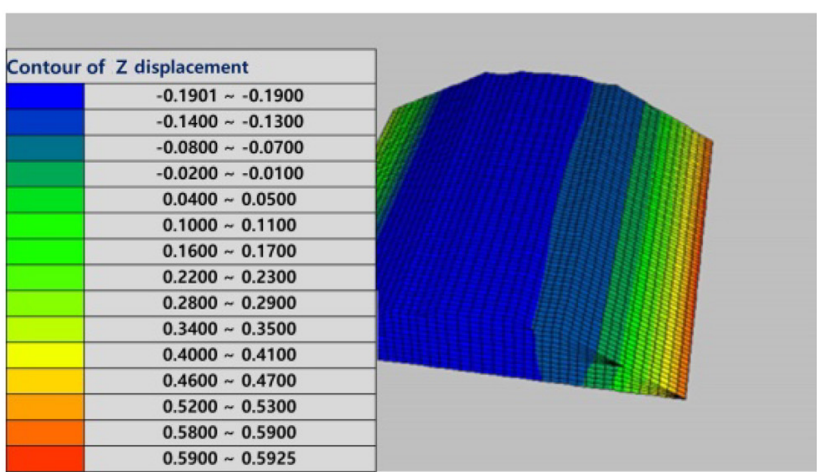

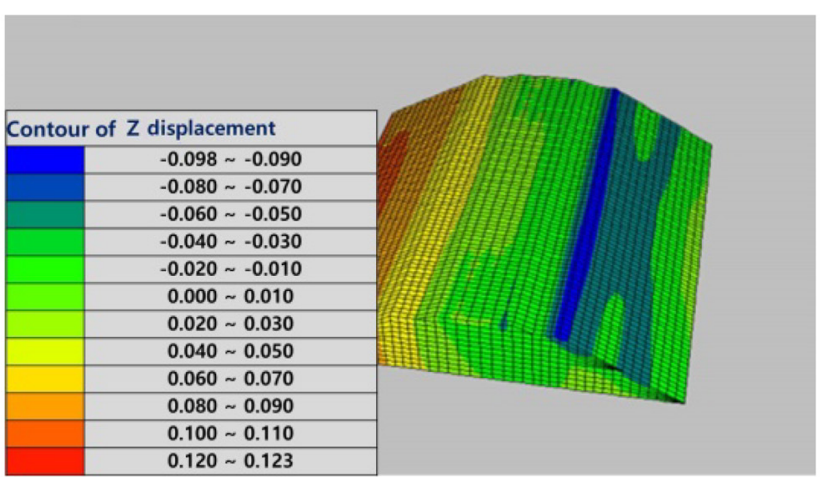

Figure 8. Vertical displacement contours of the roadbed for a cavity with a diameter of $8 \mathrm{~m}$, at the roadbed-to-cavity distance of $25 \mathrm{~m}$ : (a) GWL: ground surface and (b) GWL $=-8 \mathrm{~m}$.

The risk level has been estimated by the occurrence of roadbed settlements. The risk level has been defined by the value of the roadbed settlements relative to the allowable settlement. The risk level is defined as safe (not problematic for both ride quality and track repair), caution (not problematic for track repair), warning (between caution and danger) and danger (highly probable traffic accident) as a settlement is equal to or less than $2.5 \mathrm{~mm}$, greater than $2.5 \mathrm{~mm}$ and equal to or less than $4 \mathrm{~mm}$, greater than $4 \mathrm{~mm}$ and equal to or less than $9 \mathrm{~mm}$, and greater than $9 \mathrm{~mm}$, respectively.

\subsection{Effects of groundwater level}

In this study, the effects of GWL on the roadbed settlement are examined and the GWL is lowered until the allowable settlement value of the roadbed is satisfied. The maximum distance between the roadbed and the cavity for the analysis is determined as the maximum value for the satisfied allowable settlement with no groundwater conditions. A stability assessment of the roadbed has been carried out at the distance of $20 \mathrm{~m}$ for both 4 and $6 \mathrm{~m}$ diameter cavities and at $25 \mathrm{~m}$ for both the 8 and $10 \mathrm{~m}$ diameter cavities.

The contours of ground settlement (Fig. 8) are presented to examine the GWL effects in the case of the $8 \mathrm{~m}$ diameter cavity located at a distance of $25 \mathrm{~m}$ from the roadbed to cavity. The contours of ground settlement are presented with
GWL on the ground surface and $20 \mathrm{~m}$ below it (Fig. 8a and b). The settlement of the roadbed is highly subject to GWLs.

The roadbed settlement (Fig. 9) is highly influenced by groundwater. Ground settlement for 4 and $6 \mathrm{~m}$ diameter cavities located at a distance of $20 \mathrm{~m}$ from the roadbed (Fig. 9a and b) satisfies the allowable value for $\mathrm{GWL}=-4$ and $-12 \mathrm{~m}$, respectively. The ground settlement for 8 and $10 \mathrm{~m}$ diameter cavities located at a distance of $25 \mathrm{~m}$ from the center of the roadbed (Fig. 9c and d) has substantially decreased as the GWL is 8 and $15 \mathrm{~m}$ below the ground surface, respectively, and satisfies the allowable value as its level is 18 and $22 \mathrm{~m}$ below the ground surface, respectively. This indicates that a roadbed settlement is highly influenced by GWLs to an extent greater than even the influence of the size of the cavity.

\subsection{Risk level assessment of roadbed}

Roadbed settlements induced by the cavity near urban railways have been estimated with respect to the GWL, distance between the roadbed and cavity, and size of the cavity. As listed in Table 2, the roadbed settlement increases as the size of the cavity increases and the cavity is located close to the roadbed. As listed in Table 2, the roadbed settlement for no groundwater conditions is less than the allowable value, whereas it is in extreme danger when groundwater is present. 

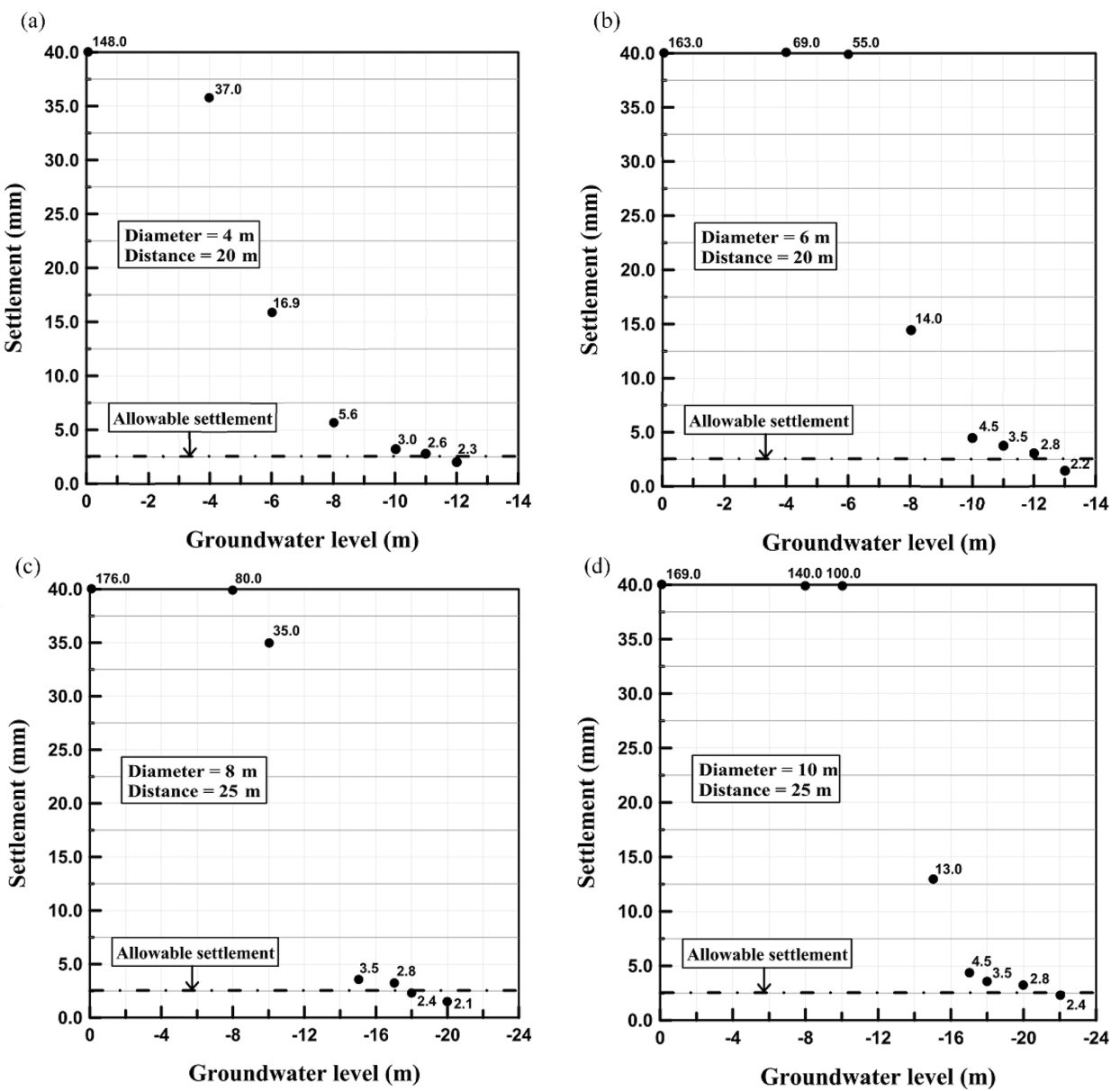

Figure 9. Roadbed settlement with respect to the groundwater level: (a) diameter of the cavity $=4 \mathrm{~m}$ and distance of roadbed from the center of the cavity $=20 \mathrm{~m}$, (b) diameter of the cavity $=6 \mathrm{~m}$ and distance of the roadbed from the center of cavity $=20 \mathrm{~m}$, (c) diameter of the cavity $=8 \mathrm{~m}$ and distance of the roadbed from the center of cavity $=25 \mathrm{~m}$, and (d) diameter of the cavity $=10 \mathrm{~m}$ and the distance of the roadbed from the center of the cavity $=25 \mathrm{~m}$.

When it is in the status of danger, train operation should be stopped and the roadbed should be reinforced or repaired. When it is in the status of caution or warning, a database of measurement sensors for urban railways should be established for real-time monitoring of the roadbed, structures and groundwater for disaster prevention.

\section{Conclusions}

The number of occurrences of ground subsidence induced by a leakage of aged pipelines for water and sewage in urban areas resulting in various sizes of cavity near the urban railway in Seoul has been found to increase and it may cause roadbed settlement to exceed the allowable value. A large-scale cavity is rarely found, but if it is close to the roadbed, the roadbed is highly influenced by the cavity and may cause train derailment.

In this study, numerical analyses are carried out to estimate roadbed stability and its risk level associated with var- ious GWLs and sizes of cavities. The analysis results show that roadbed settlement increases as the diameter $(D)$ of the cavity increases and the distance $(d)$ between the roadbed and the cavity decreases. The regression analysis results show that, as $D / d$ is greater than 0.2 and less than 0.3 , a database of measurement sensors should be established for real-time monitoring of the roadbed, structures and groundwater to prevent disasters in advance. As $D / d$ exceeds 0.35 , the roadbed settlement, which substantially increases and is in the status of danger, may result in highly probable traffic accidents. Therefore, train operation should be stopped and the roadbed should be reinforced or repaired. The effects of GWL on the roadbed settlement are examined at the distance of $20 \mathrm{~m}$ for both 4 and $6 \mathrm{~m}$ diameter cavities and at $25 \mathrm{~m}$ for both 8 and $10 \mathrm{~m}$ diameter cavities. Ground settlement for 4 and $6 \mathrm{~m}$ diameter cavities located at a distance of $20 \mathrm{~m}$ from the roadbed satisfies the allowable value for $\mathrm{GWL}=-4$ and $-12 \mathrm{~m}$, respectively. The ground settlement for 8 and $10 \mathrm{~m}$ diameter cavities located at a distance of $25 \mathrm{~m}$ from the cen- 
Table 2. Risk level of the roadbed with respect to the diameter of the cavity and the distance between the roadbed and the cavity for the groundwater condition. Safety (settlement $\leq 2.5 \mathrm{~mm}$ ), caution $(2.5 \mathrm{~mm}<$ settlement $\leq 4.0 \mathrm{~mm})$, warning $(4.0 \mathrm{~mm}<\mathrm{settlement} \leq 9.0 \mathrm{~mm})$ and danger $(9.0 \mathrm{~mm}<$ settlement $)$.

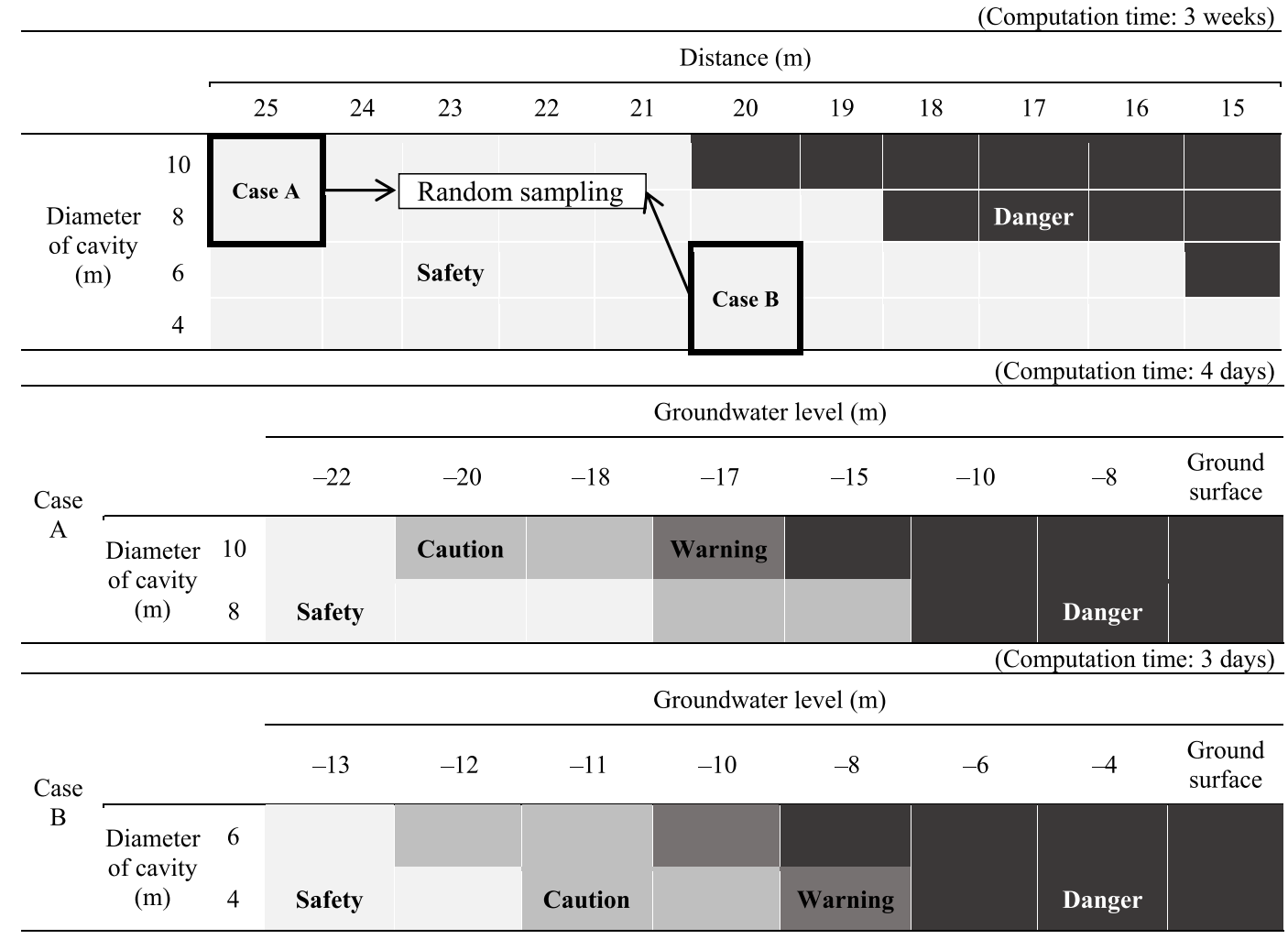

ter of the roadbed has substantially decreased as GWL is 8 and $15 \mathrm{~m}$ below the ground surface, respectively, and satisfies the allowable value as its level is 18 and $22 \mathrm{~m}$ below the ground surface, respectively. This indicates that roadbed settlement is highly influenced by GWLs to an extent greater than even the influence of the size of the cavity.

Data availability. The data are available from the authors upon request.

Competing interests. The authors declare that they have no conflict of interest.

Special issue statement. This article is part of the special issue "Landslide-road network interactions". It is not associated with a conference.

Acknowledgements. This work was supported by the 2017 INJE University research grant.
Edited by: Paolo Tarolli

Reviewed by: two anonymous referees

\section{References}

Ashfaque, K., Kladias, M., Sager, S., and Schlekat, T.: Numerical modeling to evaluate hydrological dynamics and risk assessment of bottom ash ponds at a former coal-fired electric power plant, World of coal ash conference, 8-11 May 2017, Lexington, KY, USA, 1-13, 2017.

Berrado, A., El-Loursi, E., Cherkaoui, A., and Khaddour, M.: A Framework for Risk Management in Railway Sector: Application to Road-Rail Level Crossings, Open transportation Journal, Bentham Open, 19 pp., available at: https:// hal.archives-ouvertes.fr/hal-00542424 (last access: June 2017), 2010.

Bowles, J. E.: Foundation analysis and design, 4th edn., McGrawhill, New York, USA, 658-667, 1998.

Bozzano, F., Cipriani, I., Esposito, C., Martino, S., Mazzanti, P., Prestininzi, A., Rocca, A., and Mugnozza, G. S.: Landslide risk reduction by coupling monitoring and numerical modeling, International conference Vajont 1963-2013. Thoughts and analyses after 50 years since the catastrophic landslide, 8-10 October 2013, Padua, Italy, 315-322, 2013. 
Braband, J.: Rapid Risk Assessment of Technical Systems in Railway Automation, Proc. Of the Australian System Safety Conference, 23-25 May 2012, Brisbane, Australia, 21-26, 2012.

Cai, M., Kaiser, P. K., Morioka H., Minami, M., Maejima, T., Tasaka, Y., and Kurose, H.: FLAC/PFC coupled numerical simulation of AE in large-scale underground excavations, Int. J. Rock Mech. Min., 44, 550-564, 2007.

Castellanza, R., Orlandi, G. M., Prisco, C. di, Frigerio, G., Flessati, L., Fernandez Merodo J. A., Agliardi, F., Grisi, S., and Crosta, G. B.: 3D numerical analyses for the quantitative risk assessment of subsidence and water flood due to the partial collapse of an abandoned gypsum mine, IOP C. Ser. Earth Env., 26, 1-7, 2015.

Choi, C. Y., Kim, D. S., Lee, J. W., and Shin, M. H.: Development of Database System for Management of Roadbed Settlement in High Speed Railway, Proceedings of Korean Society for Railway Fall Conference, 8-9 November 2007, Uiwang, South Korea , 496-500, 2007.

Chosun Ilbo: Excavations for 15-m diameter large-scale sinkhole Fukuoka in Japan, available at: http://news.chosun.com/site/data/ htmldir/2016/11/08/2016110801318.html, last access: December 2016.

Clough, G. W. and O'Rourke, T. D.: Construction Induced Movements of In situ Walls, Geotech. Sp., 25, 439-470, 1990.

Hakami, H.: Rock Characterisation facility (RCF) shaft sinking numerical computations using FLAC, Int. J. Rock Mech. Min., 38, 59-65, 2001.

Itasca Consulting Group, Inc.: FLAC ${ }^{3 \mathrm{D}}$ Manual-Theory and Background, Minnesota, USA, 2002.

Itasca Consulting Group, Inc.: Outline of $\mathrm{FLAC}^{3 \mathrm{D}}$, available at: https://www.itascacg.com/software/flac3d\#slideshow-6, last access: June 2016.

Jeon, S.-S.: Roadbed behavior subjected to tilting-train loading at rail joint and continuous welded rail, J. Cent. South Univ., 21, 2962-2969, 2014.

Kojima, K., Ohta, H., Iizuka, A., and Tateyama, M.: A Simple Evaluation Method of Adjacent Ground Settlement due to Excavation Work, Proceedings of the 5th International Conference of TC28 of the ISSMGE, 15-17 June 2005, Balkema, Rotterdam, the Netherlands, 719-723, 2005.

Kung, G. T., Ou, C. Y., and Juang, C. H.: Modelling Small-strain Behaviour of Taipei Clays for Finite Element Analysis of Braced Excavations, Comput. Geotech., 36, 304-319, 2009.

Kyunghang Times: Additional findings of ground subsidence in Seckchon subway in Seoul, available at: http://news.khan.co.kr/kh_news/khan_art_view.html?artid= 201408211343301\&code $=940100$, last access: December $2016 \mathrm{a}$.

Kyunghang Times: "6; sinkholes concurrence at the same time" nearby Sanseongjungang of subway 9th line station, http://sports.khan.co.kr/culture/sk_index.html?cat=view\&art_ $\mathrm{id}=201504031002483 \& \mathrm{sec} \_\mathrm{id}=562901 \& \mathrm{pt}=\mathrm{nv}$, last access: December 2016b.

Lee, H. J., Lee, Y. T., Choi, I. W., Lee, M. S., and Lee, T. G.: Investigation of Settlement of Concrete Track on High-Speed Railway Due to Groundwater Variation, Journal of the Korean Society for Railway, 20, 248-256, 2017.

Lee, J. H., Lee, H. S., and Lee, I. H.: IoT-based Convergence Technology for Urban Underground Sinkhole Prediction, in: 2015 Summer meeting of The institute of electronics and information engineering, The institute of electronics and information engineering, 7-9 July 2015, Yesan, South Korea, 1735-1737, 2015.

Lee, K. Y. and Kang, S. J.: Causes and Countermeasures of Sinkhole Swallowed the City, Issue and Analysis, 156, 1-23, 2014.

Lee, S. J., Lee, J. W., Jung, Y. N., and Cho, H. J.: Sensitivity Analysis of the Deformations caused by Cavity Generation in Subway Trackbed Foundation using the FEA, Proceedings of Korean Society for Railway Fall Conference, 22-24 October 2015, Yeosu, South Korea, 1480-1485, 2015.

Lin, H. D., Liao, H. C., Lin, K. J., Hsieh, Y. M., and Chen, C. C.: Excavation-induced Ground Settlements and responses of adjacent building at various positions using 3D decoupled analysis method, Proceedings of the 19th International Conference on Soil Mechanics and Geotechnical Engineering, 17-22 September 2017, Seoul, South Korea, 1721-1724, 2017.

Ministry of Land: Infrastructure and Transport, Seoul, Korea, available at: http://www.molit.go.kr/portal.do, last access: 15 June 2015.

Newshankuk: Asphalt road in swallowed by sinkhole brief moment, available at: http://www.newshankuk.com/news/content.asp?fs= 12\&ss=57\&news_idx=201202201707081291, last access: December 2016.

Oh, D. W., Kong, S. M., Lee, D. Y., Yoo, Y. S., and Lee, Y. J.: Effects of Reinforced Pseudo-Plastic Backfill on the Behavior of Ground around Cavity Developed due to Sewer Leakage, Journal of the Korean Geoenvironmental Society, 16, 13-22, 2015.

Ou, C.-Y., Teng, F.-C., Hsieh, P.-G., and Chien, S.-C.: Mechanism of Settlement Influence Zone due to Deep Excavation in Soft Clay, Proceedings of the 18th International Conference on Soil Mechanics and Geotechnical Engineering, 2-6 September 2013, Paris, France, 2063-2066, 2013.

Peck, R. B.: Deep Excavations and Tunneling in Soft Ground, Proceedings of 7th International Conference on Soil Mechanics and Foundation Engineering, 25-29 August 1969, Mexico City, Mexico, 225-290, 1969.

Pisani, G., Castelli, M., and Scavia, C.: Hydrogeological model and hydraulic behaviour of a large landslide in the Italian Western Alps, Nat. Hazards Earth Syst. Sci., 10, 2391-2406, https://doi.org/10.5194/nhess-10-2391-2010, 2010.

Sabzi, Z. and Fakher, A.: The Performance of Buildings adjacent to Excavation Supported by Inclined Struts, J. Civ. Eng., 13, 1-13, 2015.

Schuster, M., Kung, G. T. C., Juang, C. H., and Hashash, Y. M. A.: Simplified Model for Evaluating Damage Potential of Buildings Adjacent to a Braced Excavation, J. Geotech. Geoenviron., 135, 1823-1835, 2009.

Segye Ilbo: Half of sewage pipelines left for thirty years without maintenance leads to disaster of sinkhole, available at: http:// www.segye.com/newsView/20150322002265, last access: 3 December 2016.

Shin, E. C. and Roh, J. M.: Estimation of RPS Method Using 3Dimensional Numerical Analysis, Journal of the Korean Society for Railway, 9, 174-179, 2006.

Sisa China: Three of buildings one subsidence at Guangzhou in China, available at: http://sscn.kr/news/view.html?section= $1 \&$ category $=5 \&$ no $=3561$, last access: December 2016 .

Wikitree: "Giant sinkhole" resulting in rushed car and depth of sheriff, available at: http://www.wikitree.co.kr/main/news_view.php? $\mathrm{id}=284413$, last access: December 2016. 
Yonhap news: Large-scale at Ottawa in Canada sinkhole, available at: http://www.yonhapnews.co.kr/bulletin/2016/06/09/ 0200000000AKR20160609069000009.HTML, last access: December 2016
Zarembski, A. M. and Palese, J. W.: Managing Risk on the Railway Infrastructure, 7th World Congress on Railway Research, 4-8 June 2006, Montreal, Canada, 1-7, 2006. 